\title{
The potential of pharmacogenomics to treat drug addiction
}

\section{"...those harboring the Asp40 allele are over three-times more likely to respond to naltrexone therapy for alcohol dependence..."}

\section{Pharmacogenetics \& personalized prescribing}

Tailoring pharmacotherapy to an individual's genetic makeup to optimize treatment efficacy, while decreasing toxicity and adverse reactions seemed like science fiction only a few years ago. Genomic technology has advanced to allow personalized prescribing for many medications. Indeed, the US FDA's list of valid genomic biomarkers has expanded to include many SNPs and other gene variants that affect drug efficacy through altered pharmacokinetics and pharmacodynamics [1]. Incorporation of gene-array assay technology into mainstream clinical medicine is enhancing patient care. Pharmacogenomic biomarkers include cytochrome P450 hepatic enzyme variants that affect drug metabolism for most psychiatric medications $[2,3]$. Drugs that target serotonergic, noradrenergic and dopamine systems in psychiatric illness all have pharmacodynamic-associated gene variants that can predict therapeutic response and serious adverse drug reactions [4-8].

We previously reviewed evidence suggesting pharmacogenetics may be used to individualize drug dependence treatments $[9,10]$. Here are a few examples of medications for drug dependence disorders for which pharmacogenetic know-how may be useful to increase efficacy.

\section{Alcohol dependence: naltrexone \& topiramate}

The $\mu$-opioid antagonist naltrexone for alcohol dependence is probably the most extensively researched pharmacogenetic association to date. An asparagine-to-aspartate amino acid substitution at position 40 (Asn40Asp) in the $\mu$-opioid type 1 (OPRM1) receptor gene changes the binding of the primary endogenous ligand $\beta$-endorphin to the $\mu$-receptor [11-13]. Subjects with this SNP report altered alcohol subjective effects, and have a greater cortisol response to naltrexone $[14,15]$. Three clinical trials show that those harboring the Asp 40 allele are over three-times more likely to respond to naltrexone therapy for alcohol dependence compared with those homozygous for the Asn40 allele [16-18].

Topiramate is an anticonvulsant that is efficacious for alcohol dependence [19-22]. It may decrease alcohol craving by facilitating GABA while simultaneously inhibiting glutamatergic neurotransmission [23]. However, topiramateinduced paresthesia, fatigue, somnolence, hypoesthesia and nausea in some patients have limited its widespread use. Interestingly, Ray et al. identified a SNP in intron 9 of the glutamate receptor GluR5 gene (GRIK1) that appears related to topiramate-induced side effect severity in alcohol abusers, thereby suggesting a genetic marker to potentially determine patients poorly suited for this medication due to these side effects [24].

\section{"A rapid hepatic SNP screen is already available to help select these ultra-rapid metabolizers for buprenorphine rather than methadone pharmacotherapy."}

\section{Pharmacogenetics of methadone maintenance $\&$ buprenorphine for opiate dependence}

The opioid agonist methadone and partial agonist buprenorphine are successful replacement therapies for opiate dependence [25]. Both synthetic opioids are affected by CYP-regulated pharmacokinetics that influence their treatment efficacy [26]. Methadone and buprenorphine are both metabolized by CYP3A4, but buprenorphine is metabolized substantially less than methadone by CYP2D6 [27,28]. There have been difficulties in managing CYP2D6 ultra-rapid metabolizers taking methadone once-daily and these patients may be more optimally managed on buprenorphine for addiction treatment [29]. A rapid hepatic SNP screen is already available to help select these ultra-rapid metabolizers for buprenorphine rather than methadone pharmacotherapy.

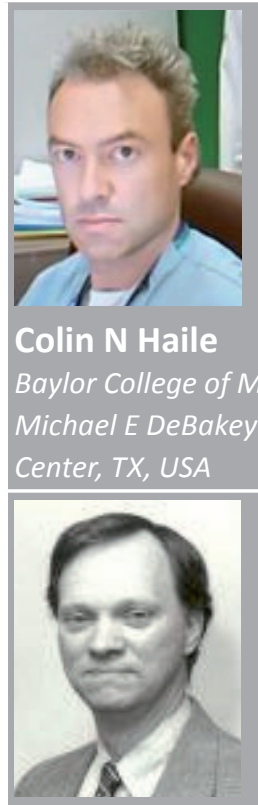

Thomas R Kosten

Author for correspondence.

Menninger Department of

Psychiatry and Behavioral

Sciences, Baylor College of

Medicine, Michael E DeBakey

VA Medical Center, 2002

Holcombe Boulevard, Houston, TX 77030, USA

Tel.: +1 7137911414 ext. 5824

Fax: +17137947938

kosten@bcm.edu 
Dopamine D2 receptors play a significant role in the reinforcing effects of many drugs of abuse, and are decreased in opiate-dependent subjects [30-33]. Interestingly, a recent study showed that patients who have the (DRD2) 957C > T polymorphism respond poorly to methadone maintenance treatment, again suggesting that this population is better treated by buprenorphine than methadone [34].

\section{"Subjects with the CYP2A6 ultra-rapid metabolizer genotype smoke more and are less likely to quit smoking..."}

\section{Nicotine replacement therapy, buproprion \& varenicline}

Nicotine influences smoking behavior and is metabolized by CYP2A6 to its inactive form cotinine. Subjects with the CYP2A6 ultra-rapid metabolizer genotype smoke more and are less likely to quit smoking, whereas those that have alleles associated with slow nicotine metabolism smoke fewer cigarettes per day and have lower risk of developing lung cancer [35-37]. This variation in metabolism also affects the efficacy of FDA-approved nicotine replacement therapy, and possibly the $\alpha 4 \beta 2$ nicotinic receptor partial agonist varenicline. Slow metabolizers using nicotine replacement reach higher plasma nicotine levels compared with normals and thus need less of the medication, which can reduce side effects and cost, and increase adherence and efficacy. An important new question is whether these pharmacogenetically selected patients might also do particularly better with varenicline than with nicotine replacement therapy $[38,39]$.

\section{Cocaine dependence: disulfiram, dexamphetamine \& methylphenidate} Although there are presently no FDA approved pharmacotherapies for stimulant addiction, the dopamine- $\beta$-hydroxylase inhibitor disulfiram $[40,41]$, and the attention deficit-hyperactivity disorder medications dexamphetamine [42-45] and methylphenidate show therapeutic promise in genetically selected subgroups of patients [46]. In both cases the relevant neurotransmitter system is dopamine. From a pharmacogenetic perspective, the functional C-1021T SNP results in significantly lower circulating $\mathrm{D} \beta \mathrm{H}$ levels and alternative pathways of converting dopamine to norepinephrine. This relatively common abnormality ( $\sim 40 \%$ of population) has been associated with lack of efficacy for disulfiram in cocaine addiction [47]. Individuals with the DAT1 genotype 3 -untranslated variable number tandem repeat polymorphism 9/9 repeats do not experience the euphoric or physiologic effects of dextroamphetamine [48]. Patients that have this polymorphism also experience higher rates of side effects from methylphenidate than attention deficit-hyperactivity disorder patients without this polymorphism [49,50]. Taken together, both of these polymorphisms, which affect dopamine metabolism and pharmacodynamics respectively, are promising candidates for improving response to these medications for stimulant abuse.

Overall, pharmacogenetics is rapidly finding a place in drug addiction pharmacotherapy in order to optimize matching of patients to our evolving new treatments.

\section{Financial \& competing interests disclosure}

The authors have no relevant affliations or financial involvement with any organization or entity with a financial interest in or financial conflict with the subject matter or materials discussed in the manuscript. This includes employment, consultancies, honoraria, stock ownership or options, expert testimony, grants or patents received or pending, or royalties.

No writing assistance was utilized in the production of this manuscript.

\section{Bibliography}

Papers of special note have been highlighted as:

- of interest

" " of considerable interest

1 Frueh FW, Amur S, Mummaneni P et al: Pharmacogenomic biomarker information in drug labels approved by the United States Food and Drug Administration: prevalence of related drug use. Pharmacotherapy 28, 992-998 (2008).

2 de Leon J: The crucial role of the therapeutic window in understanding the clinical relevance of the poor versus the ultrarapid metabolizer phenotypes in subjects taking drugs metabolized by CYP2D6 or CYP2C19. J. Clin. Psychopharmacol. 27, 241-245 (2007).

3 deLeon J, Armstrong SC, Cozza KL: Clinical guidelines for psychiatrists for the use of pharmacogenetic testing for CYP450 and CYP450 2C19. Psychosomatics 47, 75-85 (2006).

4 Szegedi A, Rujescu D, Tadic A et al.: The catechol-O-methyltransferase Val108/158Met polymorphism affects short-term treatment response to mirtazapine, but not to paroxetine in major depression. Pharmacogenomics J. 5, 49-53 (2005).
5 Schosser A, Kasper S: The role of pharmacogenetics in the treatment of depression and anxiety disorders. Int. Clin. Psychopharmacol. 24(6), 277-288 (2009).

6 Arranz MJ, de Leon J: Pharmacogenetics and pharmacogenomics of schizophrenia: a review of last decade of research. $\mathrm{Mol}$. Psychiatry 12, 707-747 (2007).

7 Opgen-Rhein C, Dettling M: Clozapineinduced agranulocytosis and its genetic determinants. Pharmacogenomics 9 , 1101-1111 (2008). 
8 de Leon J: The future (or lack of future) of personalized prescription in psychiatry. Pharmacol. Res. 59, 81-89 (2009).

9 Haile CN, Kosten TA, Kosten TR: Pharmacogenetic treatments for drug addiction: alcohol and opiates. Am. J. Drug. Alcohol. Abuse 34, 355-381 (2008).

- Interesting review.

10 Haile CN, Kosten TR, Kosten TA: Pharmacogenetic treatments for drug addiction: cocaine, amphetamine and methamphetamine. Am. J. Drug. Alcohol. Abuse 35, 161-177 (2009).

- Interesting review.

11 Bond C, LaForge KS, Tian M et al.: Single-nucleotide polymorphism in the human $\mu$ opioid receptor gene alters $\beta$-endorphin binding and activity: possible implications for opiate addiction. Proc. Natl Acad. Sci. USA 95, 9608-9613 (1998).

12 Beyer A, Koch T, Schroder H, Schulz S, Hollt V: Effect of the A118G polymorphism on binding affinity, potency and agonistmediated endocytosis, desensitization, and resensitization of the human $\mu$-opioid receptor. J. Neurochem. 89, 553-560 (2004).

13 Kroslak T, Laforge KS, Gianotti RJ, Ho A, Nielsen DA, Kreek MJ: The single nucleotide polymorphism A118G alters functional properties of the human $\mu$ opioid receptor. J. Neurochem. 103, 77-87 (2007).

14 Ray LA, Hutchison KE: A polymorphism of the $\mu$-opioid receptor gene (OPRMI) and sensitivity to the effects of alcohol in humans. Alcohol Clin. Exp. Res. 28, 1789-1795 (2004).

"II Discusses the basic findings for alcohol.

15 Ray LA, Hutchison KE: Effects of naltrexone on alcohol sensitivity and genetic moderators of medication response: a double-blind placebo-controlled study. Arch. Gen. Psychiatry 64, 1069-1077 (2007).

16 Oslin DW, Berrettini WH, O’Brien CP: Targeting treatments for alcohol dependence: the pharmacogenetics of naltrexone. Addict. Biol. 11, 397-403 (2006).

17 Anton RF, O'Malley SS, Ciraulo DA et al.: Combined pharmacotherapies and behavioral interventions for alcohol dependence: the COMBINE study: a randomized controlled trial. JAMA 295, 2003-2017 (2006).

18 Oroszi G, Anton RF, O’Malley S et al.: OPRM1 Asn40Asp predicts response to naltrexone treatment: a haplotype-based approach. Alcohol Clin. Exp. Res. 33, 383-393 (2009).

19 Dodick DW, Freitag F, Banks J et al.: Topiramate versus amitriptyline in migraine prevention: a 26-week, multicenter, randomized, double-blind, double-dummy, parallel-group noninferiority trial in adult migraineurs. Clin. Ther. 31, 542-559 (2009).

20 Roy Chengappa KN, Schwarzman LK, Hulihan JF, Xiang J, Rosenthal NR; Clinical Affairs Product Support Study-168 Investigators: Adjunctive topiramate therapy in patients receiving a mood stabilizer for bipolar I disorder: a randomized, placebocontrolled trial. J. Clin. Psychiatry 67, 1698-1706 (2006).

21 Johnson BA, Rosenthal N, Capece JA et al.: Topiramate for treating alcohol dependence: a randomized controlled trial. JAMA 298, 1641-1651 (2007).

22 Johnson BA, Rosenthal N, Capece JA et al.: Improvement of physical health and quality of life of alcohol-dependent individuals with topiramate treatment: US multisite randomized controlled trial. Arch. Intern. Med. 168, 1188-1199 (2008).

23 White HS, Smith MD, Wilcox KS: Mechanisms of action of antiepileptic drugs. Int. Rev. Neurobiol. 81, 85-110 (2007).

24 Ray LA, Miranda R Jr, MacKillop J et al.: A preliminary pharmacogenetic investigation of adverse events from topiramate in heavy drinkers. Exp. Clin. Psychopharmacol. 17, 122-129 (2009).

25 Kosten TR, Kleber HD: Buprenorphine detoxification from opioid dependence: a pilot study. Life Sci. 42, 635-641 (1988).

26 Kosten TR, Morgan C, Kosten TA: Treatment of heroin addicts using buprenorphine. Am. J. Drug. Alcohol. Abuse 17, 119-128 (1991).

27 Kobayashi K, Yamamoto T, Chiba K et al: Human buprenorphine $\mathrm{N}$-dealkylation is catalyzed by cytochrome P450 3A4. Drug Metab. Dispos. 26, 818-821 (1998).

28 Tyndale RF, Droll KP, Sellers EM: Genetically deficient CYP2D6 metabolism provides protection against oral opiate dependence. Pharmacogenetics 7, 375-379 (1997).

-1 Discusses the basic findings for nicotine.

29 Crettol S, Déglon JJ, Besson J et al.: ABCBI and cytochrome $\mathrm{P} 450$ genotypes and phenotypes: influence on methadone plasma levels and response to treatment. Clin. Pharmacol. Ther. 80, 668-681 (2006).

30 Volkow ND, Wang GJ, Fowler JS et al.: Relationship between psychostimulantinduced "high" and dopamine transporter occupancy. Proc. Natl Acad. Sci. USA 93 , 10388-10392 (1996).

31 Volkow ND, Wang GJ, Fowler JS et al.: Brain DA D2 receptors predict reinforcing effects of stimulants in humans: replications study. Synapse 46, 79-82 (2002).
32 Volkow ND, Fowler JS, Wang GJ, Swanson JM, Telang F: Dopamine in drug abuse and addiction: results of imaging studies and treatment implications. Arch. Neurol. 64, 1575-1579 (2007).

33 Wang GJ, Volkow ND, Fowler JS et al.: Dopamine D2 receptor availability in opiate-dependent subjects before and after naloxone-precipitated withdrawal. Neuropharmacology 16, 174-182 (1997).

34 Crettol S, Besson J, Croquette-Krokar M et al.: Association of dopamine and opioid receptor genetic polymorphisms with response to methadone maintenance treatment. Prog. Neuropsychopharmacol. Biol. Psychiatry 32, 1722-1727 (2008).

35 Gu DF, Hinks LJ, Morton NE, Day IN: The use of long PCR to confirm three common alleles at the CYP2A6 locus and the relationship between genotype and smoking habit. Ann. Hum. Genet. 64, 383-390 (2000).

36 Malaiyandi V, Lerman C, Benowitz NL, Jepson C, Patterson F, Tyndale RF: Impact of $C Y P 2 A 6$ genotype on pretreatment smoking behaviour and nicotine levels from and usage of nicotine replacement therapy. Mol. Psychiatry 11, 400-409 (2006).

37 Fujieda M, Yamazaki H, Saito T et al.: Evaluation of $C Y P 2 A 6$ genetic polymorphisms as determinants of smoking behavior and tobacco-related lung cancer risk in male Japanese smokers. Carcinogenesis 25, 2451-2458 (2004).

38 Mills EJ, Wu P, Spurden D, Ebbert J, Wilson K: Efficacy of pharmacotherapies for short-term smoking abstinence: a systematic review and meta-analysis. Harm. Reduct. J. 6, 25 (2009).

39 Swan GE, Valdes AM, Ring HZ et al.: Dopamine receptor DRD2 genotype and smoking cessation outcome following treatment with bupropion SR. Pharmacogenomics J. 5, 21-29 (2005).

40 Carroll KM, Fenton LR, Ball SA et al.: Efficacy of disulfiram and cognitive behavior therapy in cocaine-dependent outpatients:

a randomized placebo-controlled trial. Arch. Gen. Psychiatry 61, 264-272 (2004).

41 Carroll KM, Nich C, Ball SA et al.: One-year follow-up of disulfiram and psychotherapy for cocaine-alcohol users: sustained effects of treatment. Addiction 95 , 1335-1349 (2000).

42 Rush CR, Stoops WW, Hays LR: Cocaine effects during $\mathrm{D}$-amphetamine maintenance: a human laboratory analysis of safety, tolerability and efficacy. Drug Alcohol Depend. 99, 261-271 (2009). 
43 Shearer J, Wodak A, van Beek I, Mattick RP, Lewis J: Pilot randomized double blind placebo-controlled study of dexamphetamine for cocaine dependence. Addiction 98, 1137-1141 (2003).

44 Grabowski J, Rhoades H, Schmitz J et al.: Dextroamphetamine for cocaine-dependence treatment: a double-blind randomized clinical trial. J. Clin. Psychopharmacol. 21, 522-526 (2001).

45 Grabowski J, Rhoades H, Stotts A et al.: Agonist-like or antagonist-like treatment for cocaine dependence with methadone for heroin dependence: two double-blind randomized clinical trials. Neuropsychopharmacology 29, 969-981 (2004).
46 Tiihonen J, Kuoppasalmi K, Föhr J et al.: A comparison of aripiprazole, methylphenidate, and placebo for amphetamine dependence. Am. J. Psychiatry 164, 160-162 (2007).

47 Zabetian CP, Anderson GM, Buxbaum SG et al:: A quantitative-trait analysis of human plasma-dopamine $\beta$-hydroxylase activity: evidence for a major functional polymorphism at the DBH locus. Am. J. Genet. 68, 515-522 (2001).

48 Lott DC, Kim SJ, Cook EH, de Wit H: Dopamine transporter gene associated with diminished subjective response to amphetamine. Neuropsychopharmacology 30, 602-609 (2005)
49 Gruber R, Joober R, Grizenko N et al:: Dopamine transporter genotype and stimulant side effect factors in youth diagnosed with attention-deficit/ hyperactivity disorder. J. Child. Adolesc. Psychopharmacol. 19, 233-239 (2009).

50 Dlugos AM, Hamidovic A, Palmer AA, de Wit $\mathrm{H}$ : Further evidence of association between amphetamine response and SLC6A2 gene variants. Psychopharmacology (Berl.) 206, 501-511 (2009). 